\title{
Estimativas do Consumo e do Ganho de Peso de Bovinos, em Condições Brasileiras ${ }^{1}$
}

\section{Edilson Rezende Cappelle ${ }^{2}$, Sebastião de Campos Valadares Filho ${ }^{3}$, José Fernando Coelho da Silva ${ }^{3}$, Paulo Roberto Cecon ${ }^{4}$}

\begin{abstract}
RESUMO - Avaliou-se a predição do consumo de matéria seca e do ganho de peso diário de bovinos feita pelo Cornell Net Carbohydrate and Protein System (CNCPS) para as condições brasileiras. Foram utilizadas, neste trabalho, como fonte de dados, algumas teses defendidas no Departamento de Zootecnia da Universidade Federal de Viçosa, que continham resultados referentes ao consumo e ganho de peso dos animais. Os dados disponíveis foram testados pelo CNCPS para comparar os consumos e os ganhos de peso observados e estimados. Os consumos observados variaram muito entre as categorias animais e foram sempre subestimados pelo CNCPS. As melhores predições de consumo foram para os novilhos abatidos aos $405 \mathrm{~kg}$ e $500 \mathrm{~kg}$ de peso vivo (PV), com maior porcentagem de concentrado na dieta. A equação de regressão $\mathrm{Y}_{\mathrm{OBS}}=2,27107+0,96747 \mathrm{X}_{\mathrm{CNCPS}}\left(\mathrm{r}^{2}=0,92 ; \mathrm{P}<0,01\right)$ apresentou inclinação semelhante à da reta ideal $(\mathrm{Y}=\mathrm{X})$, podendo ser utilizada para estimar os consumos a partir de valores preditos pelo CNCPS. Os ganhos observados, quando comparados com os ganhos permitidos pelo CNCPS, apresentaram grandes variações, sendo as melhores predições de ganho de peso obtidas para novilhos abatidos com 450 e $500 \mathrm{~kg}$ de PV, alimentados com rações contendo volumoso e concentrado em proporções iguais, e para animais abatidos com $190 \mathrm{~kg}$ de PV. A equação de regressão $\mathrm{Y}_{\mathrm{OBS}}=0,82032+0,11853 \mathrm{X}_{\mathrm{CNCPS}}\left(\mathrm{r}^{2}=0,08 ; \mathrm{P}<0,05\right)$ não apresentou a mesma tendência da relação ideal, refletindo as variações nos ganhos observados e preditos. Conclui-se que o CNCPS apresentou boa predição do consumo de matéria seca, mas não foi adequado para predizer o ganho de peso.
\end{abstract}

Palavras-chave: CNCPS, consumo, ganho de peso, predição

\section{Estimates of the Intake and Weight Gain of Cattle at Brazilian Conditions}

\begin{abstract}
The dry matter intake and daily weight gain prediction of cattle by Cornell Net Carbohydrate and Protein System (CNCPS) for Brazilian conditions were evaluated. Several published thesis from Departamento de Zootecnia da Universidade Federal de Viçosa were used as a data source for this work, which contain results referent to dry matter intake and daily weight gain of the animals. The available data were tested by CNCPS to compare the estimate and absorved dry matter intake and daily weight gain. The observed dry matter intake ranged among the animal categories and was always underestimated by CNCPS. The best dry matter intake were predicted for steers slaughtered at 405 and $500 \mathrm{~kg} \mathrm{LW}$ with higher concentrate level in the diet. The regression equation $\mathrm{Y}_{\mathrm{OBS}}=2.27107+0.96747 \mathrm{X}_{\mathrm{CNCPS}}\left(\mathrm{r}^{2}=0.92 ; \mathrm{P}<0.01\right)$ showed the same tendency as the ideal relation line $(\mathrm{Y}=\mathrm{X})$ and could be used to estimate the dry matter intake from the CNCPS predicted values. The observed daily weight gain when compared to the CNCPS predicted values present high variations, and the best daily weight gain was predicted for steers slaughtered at 450 and $500 \mathrm{~kg} L W$ fed diets with forage to concentrate rations one by one and for animals slaughtered at $190 \mathrm{~kg} \mathrm{LW}$. The regression equation $\mathrm{Y}_{\mathrm{OBS}}=0.82032+0.11853 \mathrm{X}_{\mathrm{CNCPS}}$ $\left(\mathrm{r}^{2}=0.08 ; \mathrm{P}<0.05\right)$ did not present the same tendency as for the ideal straight line and showed changes on observed daily weight gain. CNCPS presented a good dry matter intake prediction, but was not adequate to predict the daily weight gain.
\end{abstract}

Key Words: CNCPS, intake, weight gain, predict

\section{Introdução}

A habilidade do animal em suprir suas necessidades nutricionais depende, principalmente, do conteúdo de energia e da proteína da dieta, que podem ser utilizadas pela microflora ruminal ou escapar da fermentação no rúmen, sendo utilizados nos outros compartimentos do trato intestinal. As digestões ruminal e pós-ruminal dependem da concentração total de carboidratos e proteínas na dieta e de suas taxas de degradação. Avaliação rotineira de dietas, desempenho animal e condições ambientais específicas para determinada localidade são essenciais para auxiliar o manejo, a alimentação, o ganho de peso e, finalmente, as decisões a serem tomadas naquela propriedade.

O Cornell Net Carbohydrate and Protein System (CNCPS), descrito por FOX et al. (1990), foi criado para ajustar os requerimentos e a utilização de nutri-

\footnotetext{
${ }^{1}$ Parte da tese de doutorado do primeiro autor.

${ }^{2}$ Professor da EAFRP - DS. E.mail: edilsoncappelle@globo.com

${ }^{3}$ Professor Titular do DZO-UFV, Ph.D. E.mail: svcfilho@mail.ufv.br

${ }^{4}$ Professor do INF-UFV.
} 
entes dentro de uma grande variação de animais, alimentos, manejo e condições ambientais. O sistema possui submodelos para funções fisiológicas e metabólicas: consumo; fermentação de carboidratos e degradação de proteínas no rúmen; digestão e absorção intestinal; excreção; utilização e partição de nutrientes para mantença, crescimento, lactação e engorda.

O CNCPS integrou o modelo de utilização de nutrientes e o modelo de requerimentos, com o objetivo de quantificar as respostas dos animais em relação às dietas. A utilização dos alimentos depende dos ingredientes presentes na dieta, da taxa de digestão ruminal de proteínas e carboidratos, da taxa de passagem, dos requerimentos para mantença e crescimento de bactérias ruminais, da taxa de produção de amônia ruminal, da digestibilidade intestinal e das condições ambientais.

O uso de uma ração para determinar a performance do animal depende do levantamento apurado das características dos alimentos com relação: à composição dos mesmos, à taxa de digestão e à taxa de passagem. O sistema assume que os alimentos são constituídos de proteínas, carboidratos, gordura, cinzas e água. As proteínas e os carboidratos são melhor subdivididos, baseados na degradação ruminal e características digestíveis. As frações de proteína e carboidratos dos alimentos são obtidas por análises químicas, que normalmente podem ser realizadas nos laboratórios das instituições de ensino e pesquisa.

LANNA et al. (1994), comparando a estimativa do CNCPS e do NRC (1984) referente ao desempenho animal com o ganho observado de 218 zebuínos, recebendo 28 dietas diferentes, concluíram que os consumos de matéria seca (MS) observados foram 21,8 e $26,7 \%$ maiores que os consumos estimados pelo CNCPS e NRC (1984), respectivamente. Relacionando os ganhos estimados pelo CNCPS $\left(\mathrm{GPD}_{\mathrm{CNCPS}}\right)$ e NRC $\left(\mathrm{GPD}_{\mathrm{NRC1}}{ }\right)$ com os ganhos de peso diários observados (GPDo em $\mathrm{kg}$ ), os autores propuseram as seguintes equações: $\mathrm{GPDo}=0,409+$ $0,68 \mathrm{GPD}_{\mathrm{CNCPS}}$ e GPDo $=0,250+0,61 \mathrm{GPD}_{\mathrm{NRC} 1984}$.

FERREIRA (1997) comparou o consumo de matéria seca e os ganhos de peso preditos pelo CNCPS com os valores observados em sua pesquisa. $\mathrm{O}$ consumo de matéria seca observado encontrou-se próximo àquele predito pelo CNCPS, mas, com relação ao ganho de peso, observou-se grande diferença, principalmente quando os animais receberam rações com menores teores de concentrado.
Visando validar o uso do CNCPS nas condições brasileiras, realizou-se este trabalho com os objetivos de comparar os consumos e ganhos de peso observados com os preditos pelo CNCPS.

\section{Material e Métodos}

O trabalho foi realizado na Universidade Federal de Viçosa (UFV), localizada em Viçosa, Minas Gerais, sendo coletados dados de algumas teses apresentadas no Departamento de Zootecnia, que continham resultados referentes ao consumo e ganho de peso de bovinos.

Inicialmente vários trabalhos foram selecionados, mas como nem todos continham os dados necessários para que pudesse ser feita a predição do desempenho dos animais pelo CNCPS (FOX et al., 1990), o número final de publicações foi reduzido. Esse número foi também reduzido em razão de se utilizar somente trabalhos com bovinos de corte.

Por outro lado, a utilização de várias raças e cruzamentos por um mesmo autor e a utilização de diferentes alimentações e pesos dos animais (iniciais e finais) dentro de um mesmo experimento ampliaram as possibilidades de comparação, contribuindo para um maior número de análises.

Após a seleção dos trabalhos, e de posse das características dos animais utilizados, do manejo e do desempenho obtido, foi feita a predição, utilizando-se o CNCPS.

O CNCPS utilizado contou com algumas modificações devido a inclusão dos resultados de análises dos alimentos feita por MALAFAIA (1997). Quando alguns dos alimentos utilizados nos trabalhos de campo não continham valores obtidos no Brasil, fez-se uma correlação, utilizando-se os alimentos listados no banco de dados do CNCPS com as características mais próximas aos utilizados nos respectivos experimentos, conforme consta na Tabela 1.

Procedimento análogo foi utilizado quando as raças ou cruzamentos dos animais utilizados não faziam parte do banco de dados do CNCPS. Procurou-se sempre respeitar as características dos animais, do ambiente e do manejo, visando minimizar essas influências nos resultados da predição.

Foram utilizados os trabalhos de SOUZA (1987), GALVÃO(1991), JORGE (1993 e 1997), FERREIRA (1997), ARAÚJO (1997) e SIGNORETTI (1998).

SOUZA (1987) trabalhou com 40 novilhas, mestiças holandês/zebu, com peso inicial médio de $236 \mathrm{~kg}$ 
Tabela 1 - Alimentos utilizados nos experimentos e alimentos correspondentes no banco de dados do CNCPS Table 1 - Feeds used in the experiments and feeds from CNCPS data

\begin{tabular}{|c|c|c|}
\hline $\begin{array}{l}\text { Alimentos utilizados } \\
\text { no experimento } \\
\text { Feeds used in the experiment }\end{array}$ & $\begin{array}{c}\text { Alimentos utilizados no banco } \\
\text { de dados do CNCPS } \\
\text { Feeds from CNCPS data }\end{array}$ & $\begin{array}{c}\text { Número dos alimentos } \\
\text { no banco de dados do CNCPS } \\
\text { Number of feeds from CNCPS data }\end{array}$ \\
\hline $\begin{array}{l}\text { Milho desintegrado com palha e sabugo } \\
\text { Corn with cob and husk }\end{array}$ & Corn Dry Ear 45 & 406 \\
\hline Fubá de milho & Milho fubá * & 436 \\
\hline Corn meal & Corn meal & \\
\hline Silagem de milho & Milho silagem * & 324 \\
\hline Corn silage & Corn silage & \\
\hline Farelo de algodão & Algodão farelo * & 524 \\
\hline Cottonseed meal & Cottonseed meal & \\
\hline Farelo de soja & Soja farelo $*$ & 523 \\
\hline Soybean meal & Soybean meal & \\
\hline Feno de capim-braquiária & Braquiária feno * & 133 \\
\hline Brachiaria grass hay & Brachiaria grass hay & \\
\hline Feno de capim-coastcross & Feno Coastcross* & 132 \\
\hline Coastcross hay & Coastcross hay & \\
\hline Uréia & Uréia & 522 \\
\hline Urea & Urea & \\
\hline Mistura mineral & Minerais & 999 \\
\hline Mineral mix & Minerals & \\
\hline
\end{tabular}

${ }^{*}$ Alimentos com a composição modificada pela inclusão dos resultados obtidos por MALAFAIA (1997).

${ }^{*}$ Feeds with modified composition after inclusion of results obtained from MALAFAIA (1997).

e idade média de 16 meses, alimentadas com as seguintes rações: milho desintegrado com palha e sabugo e farelo de algodão (T1); milho desintegrado com palha e sabugo, farelo de algodão e $1,25 \%$ de uréia (T2); milho desintegrado com palha e sabugo, farelo de algodão e $2,50 \%$ de uréia (T3); milho desintegrado com palha e sabugo, farelo de algodão e 3,75\% de uréia (T4) e milho desintegrado com palha e sabugo, farelo de algodão e 4,30\% de uréia (T5). Todas as misturas concentradas foram isoprotéicas, com $20 \%$ de proteína bruta (PB) e foram adicionadas à silagem de milho na proporção de $20 \%$, na base da matéria natural, obtendo-se um teor de $12 \%$ de PB na matéria seca da ração completa.

GALVÃO (1991) utilizou em seu estudo 48 bovinos machos, não castrados, sendo 16 nelores (NE), 16 F1 nelore/marchigiana (NM) e $16 \mathrm{~F}_{1}$ nelore/limousin (NL), com peso vivo inicial médio de 253, 330 e $339 \mathrm{~kg}$, respectivamente. Os animais dos três grupos tinham idade média de 20 meses. A alimentação foi realizada com ração única, ad libitum, sendo constituída de feno picado de capim-braquiária (Brachiaria decumbens, Stapf), farelo de soja, milho desintegrado com palha e sabugo (MDPS) e mistura mineral, mantendo-se a proporção concentrado:volumoso de 1:1.

JORGE (1993) trabalhou com 46 bovinos machos, não castrados, sendo 16 Nelore (NE), 16 1⁄2 Holandês/
Nelore (HN) e 14 1/2 Nelore/bimestiço (BM), com idade média de 24 meses e pesos vivos iniciais de 300 , 406 e $360 \mathrm{~kg}$, respectivamente. Os animais receberam ração ad libitum, constituída de $50 \%$ de feno de capim-braquiária (Brachiaria decumbens, Stapf) e $50 \%$ de uma mistura constituída de farelo de soja, milho desintegrado com palha e sabugo (MDPS), uréia, fosfato bicálcico, sal e mistura mineral.

Em 1997, JORGE avaliou 63 animais machos, não castrados, sendo 16 Gir, 16 Guzerá, 15 Nelore e 16 Mocho Tabapuã, com idade média de 24 meses e peso vivo médio de 358, 362, 376 e $369 \mathrm{~kg}$, respectivamente. Os animais receberam ração composta de $50 \%$ de feno de capim-braquiária (Brachiaria decumbens, Stapf) e $50 \%$ de uma mistura de fubá de milho, farelo de soja, uréia e mistura mineral, sendo abatidos em três pesos preestabelecidos: 405, $450 \mathrm{e}$ $500 \mathrm{~kg}$, correspondentes às categorias I, II e III, respectivamente.

FERREIRA (1997) utilizou 29 animais machos, não castrados, provenientes de cruzamentos Simental x Nelore, com idade média de 17 meses e peso inicial de $354 \mathrm{~kg}$. Os animais receberam cinco tratamentos: $25 \%$ de concentrado (T1); 37,5\% de concentrado (T2); 50\% de concentrado (T3); $62,5 \%$ de concentrado (T4) e $75 \%$ de concentrado (T5). O concentrado foi constituído de fubá de milho, farelo de soja, 
uréia e mistura mineral e o volumoso, fornecido a todos os animais, constituiu-se de uma mistura de partes iguais de feno de capim-coastcross e feno de capim-braquiária.

ARAÚJO (1997) trabalhou com 32 bezerros $1 / 2$ sangue Holandês/Zebu, machos, não castrados, com peso médio inicial de $60 \mathrm{~kg}$ e idade aproximada de 2 meses. Utilizaram-se 16 animais do grupo I (abate aos $300 \mathrm{~kg}$ ) e 16 animais do grupo II (abate aos $180 \mathrm{~kg}$ ), alimentados à vontade e distribuídos em quatro tratamentos: $90 \%$ de concentrado (T1); $75 \%$ de concentrado (T2); 60\% de concentrado (T3) e $45 \%$ de concentrado (T4). Os concentrados eram compostos de fubá de milho, farelo de soja e mistura mineral e o volumoso fornecido foi feno de capim-coastcross.

SIGNORETTI (1998) avaliou 36 bezerros holandeses puros por cruza, sendo 20 no grupo I (abate aos $190 \mathrm{~kg}$ ) e 16 no grupo II (abate aos $300 \mathrm{~kg}$ ), alimentados ad libitum e distribuídos em quatro tratamentos: $90 \%$ de concentrado (T1); $75 \%$ de concentrado (T2); $60 \%$ de concentrado (T3) e $45 \%$ de concentrado (T4). Os concentrados eram compostos de fubá de milho, farelo de soja e mistura mineral, e o volumoso fornecido a todos os animais foi feno de capim-coastcross.

\section{Resultados e Discussão}

Constam da Tabela 2 os consumos de matéria seca e os ganhos de peso observados e os preditos pelo CNCPS. Verifica-se que os consumos observados descritos por SOUZA (1987) foram superiores aos preditos pelo CNCPS, ocorrendo redução dos valores observados, com o aumento da substituição do farelo de algodão pela uréia (T1 para T5), sendo que a diferença entre os consumos observados e preditos variou de 31 a $40 \%$.

Comparando os ganhos de peso obtidos e os preditos pelo CNCPS, observa-se que os ganhos observados foram de 27 a $35 \%$ inferiores aos preditos, de acordo com a disponibilidade de energia metabolizável. Observou-se que tanto os ganhos observados como os estimados declinaram com o aumento da porcentagem de uréia na alimentação.

Os consumos observados por GALVÃO (1991) foram 23 a 47\% maiores que os preditos (Tabela 3). Os ganhos de peso observados mostraram dois comportamentos: um para os animais $1 / 2$ Nelore $\mathrm{x}$ Limousin, que apresentaram ganho observado 3\% su-
Tabela 2 - Consumos médios de matéria seca ( $\mathrm{kg} / \mathrm{dia})$ e ganhos médios de peso vivo (kg/dia), observados e preditos pelo CNCPS, obtidos para os cinco tratamentos (SOUZA, 1987)

Table 2 - Average dry matter ( $\mathrm{kg} /$ day) intake and live weight gain ( $\mathrm{kg} /$ day), observed and predicted by CNCPS, obtained for the five treatments (SOUZA, 1987)

\begin{tabular}{llll}
\hline Itens & \multicolumn{3}{c}{ Valores } \\
& \multicolumn{3}{c}{ Values } \\
\cline { 2 - 4 } & $\begin{array}{c}\text { Observados } \\
\text { Observed }\end{array}$ & $\begin{array}{c}\text { Preditos } \\
\text { Predicted }\end{array}$ & $(\%)^{1}$ \\
\hline
\end{tabular}

Consumo de matéria seca $(\mathrm{kg} / \mathrm{dia})$

Tratamento 1

Tratamento 2

Tratamento 3

Tratamento 4 Dry matter intake ( $\mathrm{kg} /$ day)

Tratamento 5

$\begin{array}{lll}8,70 & 6,20 & 140 \\ 8,50 & 6,20 & 137 \\ 8,40 & 6,20 & 135 \\ 8,40 & 6,20 & 135 \\ 8,10 & 6,20 & 131\end{array}$

\begin{tabular}{lccc} 
& \multicolumn{3}{c}{$\begin{array}{c}\text { Ganhos de peso }(\mathrm{kg} / \mathrm{dia}) \\
\text { Weight gain }(\mathrm{kg} / \text { day) }\end{array}$} \\
Tratamento 1 & 0,81 & 1,12 & 72 \\
Tratamento 2 & 0,76 & 1,09 & 70 \\
Tratamento 3 & 0,77 & 1,05 & 73 \\
Tratamento 4 & 0,68 & 1,04 & 65 \\
Tratamento 5 & 0,68 & 1,00 & 68 \\
\hline 10bservado/predito x 100 (observed/predicted x 100). \\
Tratamento (treatment).
\end{tabular}

Tabela 3 - Consumos médios de matéria seca ( $\mathrm{kg} / \mathrm{dia})$ e ganhos médios de peso vivo (kg/dia), observados e preditos pelo CNCPS, obtidos para os animais Nelore, $1 / 2$ Nelore x Marchigiana e $1 / 2$ Nelore $x$ Limousin (GALVÃO, 1991)

Table 3 - Average dry matter ( $\mathrm{kg} /$ day) intake and live weight gain (kg/day), observed and predicted by CNCPS, obtained for Nellore, $1 / 2$ Nellore $x$ Marchigiana e $1 / 2$ Nellore $x$ Limousin (GALVÃO, 1991)

\begin{tabular}{|c|c|c|c|}
\hline \multirow[t]{2}{*}{ Itens } & \multicolumn{3}{|c|}{$\begin{array}{l}\text { Valores } \\
\text { Values }\end{array}$} \\
\hline & $\begin{array}{c}\text { Observados } \\
\text { Observed }\end{array}$ & $\begin{array}{l}\text { Preditos } \\
\text { Predicted }\end{array}$ & $(\%)^{1}$ \\
\hline & \multicolumn{3}{|c|}{$\begin{array}{c}\text { Consumo de matéria seca }(\mathrm{kg} / \mathrm{dia}) \\
\text { Dry matter intake }(\mathrm{kg} / \text { day })\end{array}$} \\
\hline Nelore & 9,10 & 6,20 & 147 \\
\hline $1 / 2$ Nelore $x$ Marchigiana & 9,50 & 7,70 & 123 \\
\hline \multirow{2}{*}{$1 / 2$ Nelore $x$ Limousin } & 10,30 & 7,90 & 130 \\
\hline & \multicolumn{3}{|c|}{$\begin{array}{l}\text { Ganho de peso }(\mathrm{kg} / \mathrm{dia}) \\
\text { Weight gain }(\mathrm{kg} / \text { day })\end{array}$} \\
\hline Nelore & 0,95 & 1,48 & 64 \\
\hline $1 / 2$ Nelore $x$ Marchigiana & 1,19 & 1,32 & 90 \\
\hline $1 / 2$ Nelore $x$ Limousin & 1,21 & 1,17 & 103 \\
\hline
\end{tabular}

Rev. bras. zootec., 30(6):1857-1865, 2001 
perior ao predito; outro para os animais Nelore e $1 / 2$ Nelore x Marchigiana, que apresentaram ganhos observados $36 \%$ e $10 \%$ inferiores aos preditos pelo CNCPS, respectivamente. As diferenças verificadas para os animais cruzados (F1) 1/2 Nelore $x$ Limousin e $1 / 2$ Nelore $\mathrm{x}$ Marchigiana foram menores, o que pode sugerir uma tendência dos animais cruzados apresentarem desempenhos mais próximos dos preditos pelo CNCPS.

$\mathrm{Na}$ Tabela 4 estão apresentados os dados de consumo observados por JORGE (1993) e os preditos pelo CNCPS. Observa-se que os consumos observados foram de 17 a $24 \%$ superiores aos preditos. Os ganhos observados foram de 21 a $32 \%$ inferiores aos previstos em função da disponibilidade de energia metabolizável.

Os resultados obtidos por JORGE (1997), com relação ao consumo e ganho, comparados aos preditos pelo CNCPS, estão apresentados na Tabela 5, separados por raça e por categoria. Todos os consumos observados foram superiores aos preditos pelo CNCPS. Os animais da categoria I (peso final de abate: $405 \mathrm{~kg}$ ) apresentaram consumos observados, de 6 a 22\% superiores aos preditos e, dentre eles, a raça Gir foi a que apresentou os valores mais próximos aos preditos. Nas categorias II e III, a diferença entre consumos observados e preditos aumentou,

Tabela 4 - Consumos médios de matéria seca ( $\mathrm{kg} / \mathrm{dia}$ ) e ganhos médios de peso vivo (kg/dia), observados e preditos pelo CNCPS, obtidos para os animais Nelore, $1 / 2$ Holandês x Nelore e $1 / 2$ Nelore x mestiço (JORGE, 1993)

Table 4 - Average dry matter ( $\mathrm{kg} /$ day) intake and live weight gain (kg/day), observed and predicted by CNCPS, obtained for Nellore, $1 / 2$ Holandês $x$ Nellore e $1 / 2$ Nellore $x$ crossbred (JORGE, 1993)

\begin{tabular}{|c|c|c|c|}
\hline \multirow[t]{2}{*}{ Itens } & \multicolumn{3}{|c|}{$\begin{array}{l}\text { Valores } \\
\text { Values }\end{array}$} \\
\hline & $\begin{array}{l}\text { Observados } \\
\text { Observed }\end{array}$ & $\begin{array}{l}\text { Preditos } \\
\text { Predicted }\end{array}$ & $(\%)^{1}$ \\
\hline & \multicolumn{3}{|c|}{$\begin{array}{c}\text { Consumo de matéria seca }(\mathrm{kg} / \mathrm{dia}) \\
\text { Dry matter intake }(\mathrm{kg} / \text { day })\end{array}$} \\
\hline Nelore & 8,60 & 7,10 & 121 \\
\hline $1 / 2$ Holandês x Nelore & 10,80 & 9,20 & 117 \\
\hline \multirow[t]{2}{*}{ 1/2 Nelore x Mestiço } & 10,40 & 8,40 & 124 \\
\hline & \multicolumn{3}{|c|}{$\begin{array}{l}\text { Ganhos de peso }(\mathrm{kg} / \mathrm{dia}) \\
\text { Weight gain }(\mathrm{kg} / \text { day })\end{array}$} \\
\hline Nelore & 0,80 & 1,18 & 68 \\
\hline $1 / 2$ Holandês x Nelore & 0,83 & 1,05 & 79 \\
\hline $1 / 2$ Nelore $x$ Mestiço & 0,80 & 1,12 & 71 \\
\hline
\end{tabular}

${ }^{1}$ Observado/predito x 100 (observed/predicted $\times 100$ ). variando de 21 a $27 \%$ e 28 a $65 \%$, respectivamente.

Verifica-se que, com o aumento do peso de abate, os consumos médios dos animais aumentaram, ocorrendo também aumentos nas diferenças entre os consumos observados e preditos.

Os ganhos de peso observados para os animais da categoria I foram superiores aos permitidos pela energia metabolizável disponível de acordo com o CNCPS, variando de 17 a 54\%. Para a categoria II, os ganhos observados mostraram-se também superiores aos preditos, mas verifica-se maior proximidade entre os valores, com diferença máxima de $21 \%$. Já para os animais da categoria III, os ganhos observados foram menores que os preditos pelo CNCPS, ficando a diferença entre 5 e 19\%. Considerando-se os animais abatidos nas três categorias, o CNCPS mostrou maior precisão ao estimar os ganhos de peso dos animais abatidos na categoria III (abate aos $500 \mathrm{~kg}$ ).

Os consumos observados por FERREIRA (1997) apresentaram-se superiores aos preditos pelo CNCPS, variando de 11 a 35\% (Tabela 6). Para o tratamento 3, em que foram utilizadas proporções iguais de concentrado e volumoso, a estimativa do CNCPS foi mais próxima do valor observado, sugerindo melhor predição de consumo pelo CNCPS, com dietas que têm proporções semelhantes de concentrado e volumoso.

Os ganhos de peso observados apresentaram grandes variações, quando comparados aos preditos pelo CNCPS, obtendo valores iguais e até $167 \%$ maiores. As melhores predições foram para o tratamento 5, que apresentava maiores níveis de concentrado. Verifica-se que, para o tratamento 1 , tanto o consumo como o ganho de peso sofreram grandes variações com relação a estimativa do CNCPS, o que poderia indicar que, com pequenas quantidades de concentrado, o sistema de Cornell não forneceu boa predição para os animais analisados. Já para os tratamentos com maior percentagem de concentrado (T4 e T5), os ganhos observados estiveram muito próximos dos ganhos preditos, indicando maior precisão da estimativa do CNCPS nesses casos.

Comparando os consumos observados por ARAÚJO (1997) e os preditos pelo CNCPS, observa-se que os valores observados foram superiores aos preditos (Tabela 7), sendo que na categoria I as diferenças foram iguais ou superiores a $100 \%$, apresentando maior diferença com o aumento do nível de volumoso na dieta. Pode-se considerar que, para bezerros abatidos tanto aos $180 \mathrm{~kg}$ como aos $300 \mathrm{~kg}$, o CNCPS não estimou com precisão o consumo desses animais. 
Tabela 5 - Consumos médios de matéria seca ( $\mathrm{kg} / \mathrm{dia})$ e ganhos médios de peso vivo (kg/dia), observados e preditos pelo CNCPS, obtidos para os animais das raças Nelore, Gir, Guzerá e Tabapuã (JORGE, 1997)

Table 5 - Average dry matter (kg/day) intake and live weight gain (kg/day), observed and predicted by CNCPS, obtained for Nellore, Gyr, Guzera and Tabapuã (JORGE, 1997)

\begin{tabular}{|c|c|c|c|c|}
\hline \multicolumn{2}{|c|}{ Itens } & \multicolumn{3}{|c|}{$\begin{array}{l}\text { Valores } \\
\text { Values }\end{array}$} \\
\hline & & \multirow[t]{2}{*}{$\begin{array}{l}\text { Observados } \\
\text { Observed }\end{array}$} & $\begin{array}{l}\text { Preditos } \\
\text { Predicted }\end{array}$ & $(\%)^{1}$ \\
\hline \multicolumn{4}{|c|}{$\begin{array}{c}\text { Consumos de matéria seca }(\mathrm{kg} / \mathrm{dia}) \\
\text { Dry matter intake ( } \mathrm{kg} / \text { day })\end{array}$} & \\
\hline \multirow[t]{3}{*}{ Nelore } & I & 9,10 & 8,20 & 111 \\
\hline & II & 10,50 & 8,30 & 127 \\
\hline & III & 13,50 & 8,20 & 165 \\
\hline \multirow{3}{*}{ Gir } & I & 8,50 & 8,00 & 106 \\
\hline & II & 9,70 & 8,00 & 121 \\
\hline & III & 10,20 & 8,00 & 128 \\
\hline \multirow[t]{3}{*}{ Guzerá } & I & 9,20 & 8,00 & 115 \\
\hline & II & 10,10 & 8,10 & 125 \\
\hline & III & 10,60 & 8,10 & 131 \\
\hline \multirow[t]{5}{*}{ Tabapuã } & I & 9,90 & 8,10 & 122 \\
\hline & II & 10,00 & 8,20 & 122 \\
\hline & III & 10,90 & 8,20 & 133 \\
\hline & & & de peso & \\
\hline & & & ht gain $(\mathrm{kg})$ & \\
\hline \multirow[t]{3}{*}{ Nelore } & I & 1,03 & 0,67 & 154 \\
\hline & II & 1,05 & 0,87 & 121 \\
\hline & III & 1,00 & 1,23 & 81 \\
\hline \multirow[t]{3}{*}{ Gir } & I & 0,91 & 0,64 & 142 \\
\hline & II & 0,94 & 0,83 & 113 \\
\hline & III & 0,89 & 0,94 & 95 \\
\hline \multirow[t]{3}{*}{ Guzerá } & I & 0,91 & 0,71 & 128 \\
\hline & II & 0,94 & 0,86 & 109 \\
\hline & III & 0,88 & 0,97 & 91 \\
\hline \multirow[t]{3}{*}{ Tabapuã } & I & 0,89 & 0,76 & 117 \\
\hline & II & 0,92 & 0,82 & 112 \\
\hline & III & 0,87 & 0,99 & 88 \\
\hline
\end{tabular}

1 Observado/predito $\times 100$ (observed/predicted $\times 100$ ).

2 I, II e III, abate aos 405, 450 e $500 \mathrm{~kg}$, respectivamente (I and II, slaughter at 400, 450 and $500 \mathrm{~kg}$, respectively).

Os ganhos observados para os animais da categoria I (abate aos $300 \mathrm{~kg}$ ) apresentaram-se 39 a 64\% inferiores aos preditos pelo CNCPS. Com o aumento da porcentagem de volumoso na dieta, reduziram-se as diferenças entre ganhos observados e preditos. Para a categoria II, verifica-se que os ganhos observados foram inferiores aos previstos, em função da disponibilidade de energia metabolizável para os tratamentos 1, 2 e 3, apesar de a diferença ser apenas de $7 \%$ no tratamento 3 . Já no tratamento 4 , categoria II, o ganho observado foi exatamente igual ao predito pelo CNCPS, mostrando que, com maior nível de volumoso, o CNCPS apresentou boa predição do ganho de peso dos animais abatidos aos $180 \mathrm{~kg}$.

Os consumos observados por SIGNORETTI (1998) foram superiores aos consumos preditos pelo CNCPS (Tabela 8). Verifica-se que os consumos observados variaram de 60 a $71 \%$ para os animais da categoria I e de 108 a $124 \%$ para os animais da categoria II, sugerindo que o CNCPS não foi adequado para predizer o consumo dos animais utilizados.

Os ganhos observados para os animais da categoria I estiveram próximos dos preditos, nos tratamentos 1,2 e 3 (rações ricas em concentrado), tendo uma variação máxima de $11 \%$. No caso do tratamento 4 , que concorda com FERREIRA (1997), o ganho observado foi $46 \%$ superior ao predito, sugerindo pouca precisão da predição do CNCPS para alimentação com menor percentagem de concentrado.

Para a categoria II, os ganhos de peso observados foram de 23 a $49 \%$ inferiores aos preditos pelo CNCPS. Avaliando-se as duas categorias, verificase que o CNCPS estimou com melhor precisão os ganhos de peso dos animais da categoria I (190 kg), 
Tabela 6 - Consumos médios de matéria seca ( $\mathrm{kg} / \mathrm{dia})$ e ganhos médios de peso vivo ( $\mathrm{kg} / \mathrm{dia})$, observados e preditos pelo CNCPS, obtidos para os cinco tratamentos (FERREIRA, 1997)

Table 6 - Average dry matter ( $\mathrm{kg} /$ day) intake and live weight gain (kg/day), observed and predicted by CNCPS, obtained for the five treatments (FERREIRA, 1997)

\begin{tabular}{llll}
\hline Itens & \multicolumn{3}{c}{ Valores } \\
& \multicolumn{3}{c}{ Values } \\
\cline { 2 - 4 } & $\begin{array}{c}\text { Observados } \\
\text { Observed }\end{array}$ & $\begin{array}{c}\text { Preditos } \\
\text { Predicted }\end{array}$ & $(\%)^{1}$ \\
\hline
\end{tabular}

Consumo de matéria seca (kg/dia)

\begin{tabular}{lccc} 
& \multicolumn{3}{c}{ Dry matter intake (kg/day) } \\
\hline Tratamento 1 & 9,30 & 6,90 & 135 \\
Tratamento 2 & 9,70 & 7,70 & 126 \\
Tratamento 3 & 9,20 & 8,30 & 111 \\
Tratamento 4 & 10,10 & 8,40 & 120 \\
Tratamento 5 & 10,40 & 8,40 & 124 \\
& \multicolumn{3}{c}{ Ganhos de peso $(\mathrm{kg} / \mathrm{dia})$} \\
Tratamento 1 & 0,80 & Weight gain $(\mathrm{kg} /$ day) \\
Tratamento 2 & 1,00 & 0,30 & 267 \\
Tratamento 3 & 1,10 & 0,60 & 167 \\
Tratamento 4 & 1,40 & 1,80 & 138 \\
Tratamento 5 & 1,60 & 1,60 & 108 \\
\hline
\end{tabular}

${ }_{1}^{1}$ Observado/predito x 100 (observed/predicted $\times 100$ ).

Tratamento (treatment). principalmente para os tratamentos 1,2 e 3 , que continham mais concentrado nas rações.

Obteve-se a equação de regressão linear entre os consumos observados e preditos pelo CNCPS: $\mathrm{Y}_{\mathrm{OBS}}=2,27107+0,967479 \mathrm{X}_{\mathrm{CNCPS}}\left(\mathrm{r}^{2}=0,92\right.$; $\mathrm{P}<0,01)$. Pelo teste " $\mathrm{t}$ ", verifica-se que $\mathrm{B}_{1}=1$ e que $\mathrm{B}_{0} \neq 0$, o que indica que a inclinação da reta obtida pela regressão é semelhante à da reta ideal $(\mathrm{Y}=\mathrm{X})$, para todos os experimentos avaliados em conjunto, significando que o CNCPS foi adequado para predizer o consumo dos animais (Figura 1).

A equação de regressão linear obtida entre os ganhos de peso observados ( $\left.\mathrm{Y}_{\mathrm{OBS}}\right)$ e preditos $\left(\mathrm{X}_{\mathrm{CNCPS}}\right)$ foi $\mathrm{Y}_{\mathrm{OBS}}=0,820324+0,118537 \mathrm{X}_{\mathrm{CNCPS}}\left(\mathrm{r}^{2}=0,08\right.$; $\mathrm{P}<0,05)$. Pelo teste " $t$ ", verifica-se que $\mathrm{B}_{1} \neq 1$ e $\mathrm{B}_{0} \neq 0$, o que confirma a tendência da reta obtida pela regressão em apresentar tanto inclinação como intercepto diferentes da reta ideal $(\mathrm{Y}=\mathrm{X})$, resultando em valores diferentes da relação ideal (Figura 2).

O desempenho dos animais apresentou diferenças entre os valores observados e preditos pelo CNCPS, endossando os estudos de LANNA et al.

Tabela 7 - Consumos médios de matéria seca ( $\mathrm{kg} / \mathrm{dia})$ e ganhos médios de peso vivo ( $\mathrm{kg} / \mathrm{dia})$, observados e preditos pelo CNCPS, obtidos para os quatro tratamentos (ARAÚJO, 1997)

Table 7 - Average dry matter ( $\mathrm{kg} /$ day) intake and live weight gain ( $\mathrm{kg} /$ day), observed and predicted by CNCPS, obtained for the four treatments (ARAÚJO, 1997)

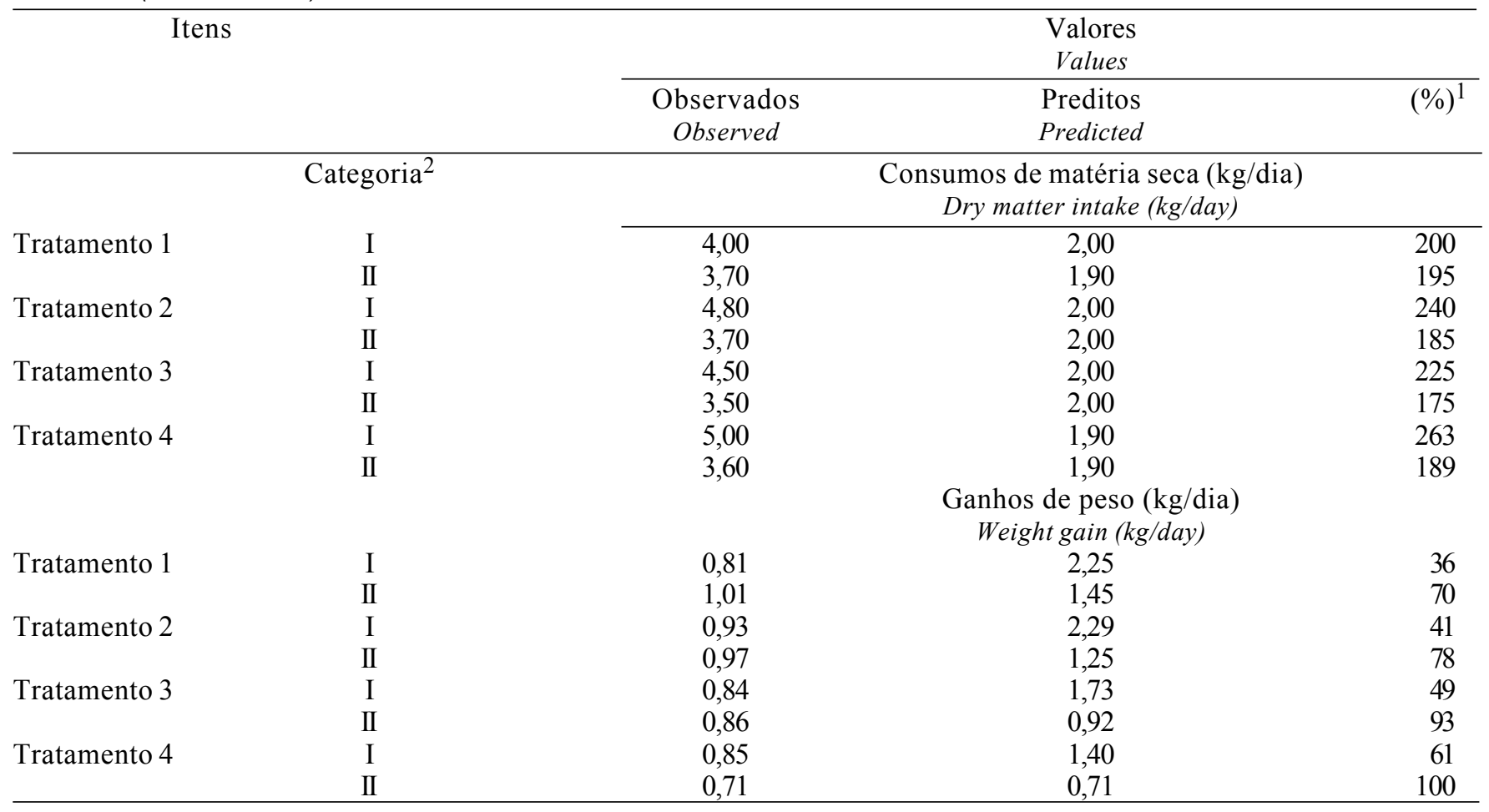

${ }_{1}^{1}$ Observado/predito $\times 100$ (observed/predicted $\times 100$ ).

2 I e II, abate aos 300 e $180 \mathrm{~kg}$, respectivamente (I and II, slaughter at 300 and $180 \mathrm{~kg}$, respectively).

Tratamento (treatment). 
Tabela 8 - Consumos médios de matéria seca (kg/dia) e ganhos médios de peso vivo (kg/dia), observados e preditos pelo CNCPS, obtidos para os quatro tratamentos (SIGNORETTI, 1998)

Table 8 - Average dry matter (kg/day) intake and live weight gain (kg/day), observed and predicted by CNCPS, obtained for the four treatments (SIGNORETTI, 1998)

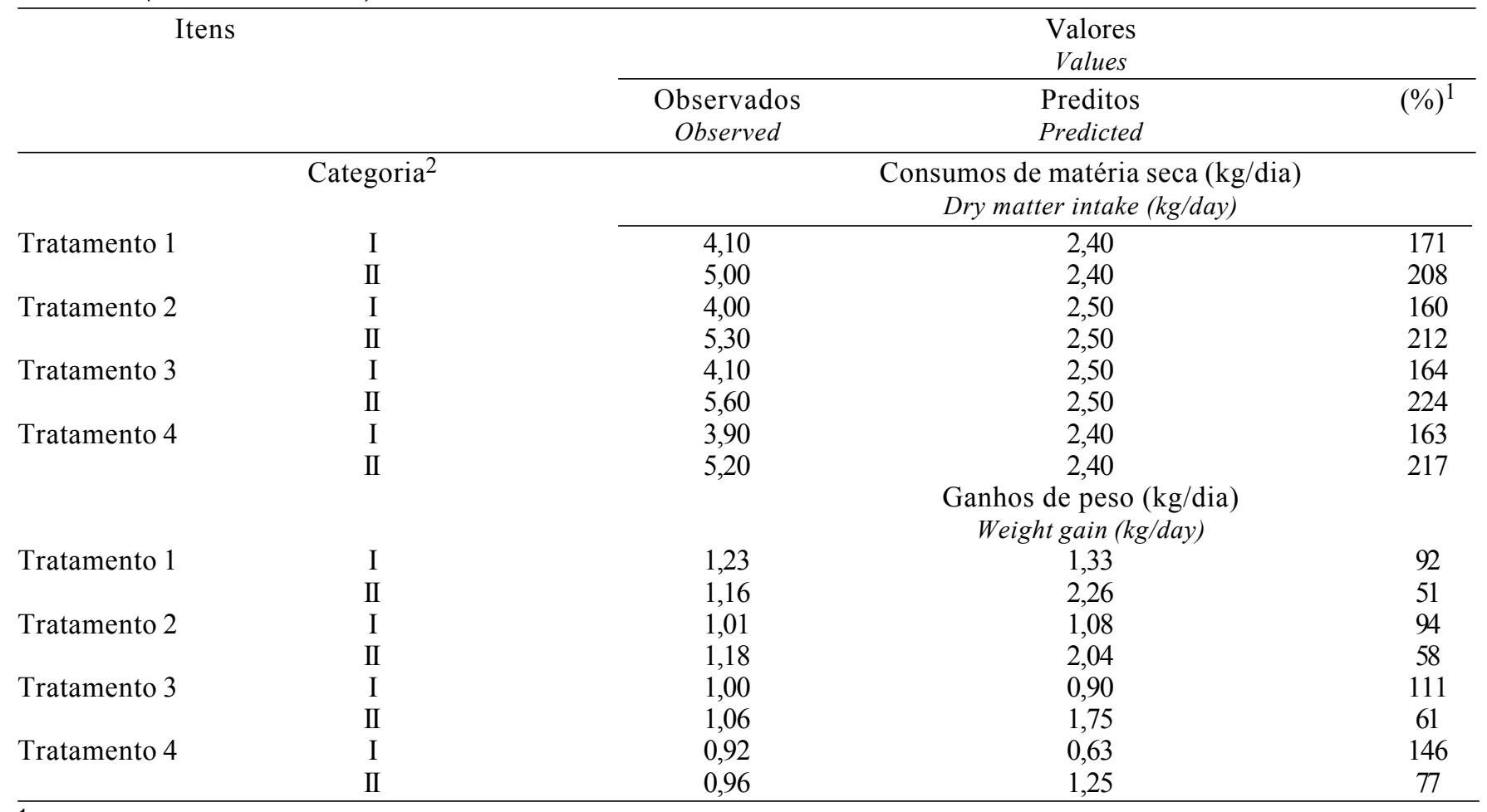

${ }^{1}$ Observado/predito $\times 100$ (observed/predicted $\times 100$ ).

2I e II, abate aos 190 e $300 \mathrm{~kg}$, respectivamente (I and II, slaughter at 190 and $300 \mathrm{~kg}$, respectively).

Tratamento (treatment).

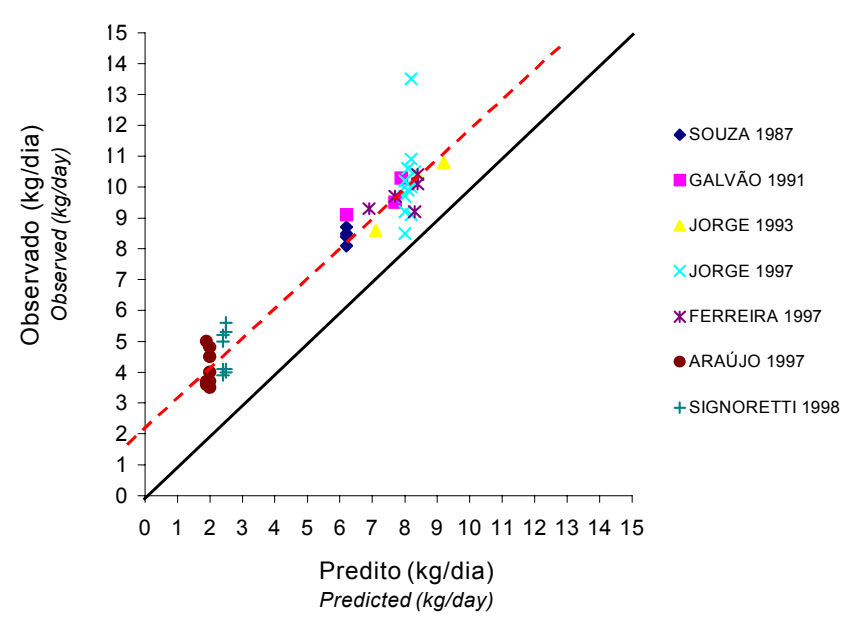

Figura 1 - Relação entre os consumos observados e preditos pelo CNCPS para todos experimentos estudados. A linha contínua representa a relação ideal $(Y=X)$ e a linha pontilhada é a regressão linear $Y_{\text {OBS }}=2,27107+0,967479 X_{\text {CNCPS }}$, em que $Y$ é o consumo observado e $X$, o consumo predito pelo CNCPS.

Figure 1 - Relation among observed and predicted intakes by CNCPS for all studied experiments. The continuous line represent the ideal relation $(Y=X)$ and the discontinuous line is the linear regression $Y_{O B S}=$ $2,27107+0,967479 X_{C N C P S}$, where $Y$ is the observed intake and $X$ is the predicted intake by CNCPS.

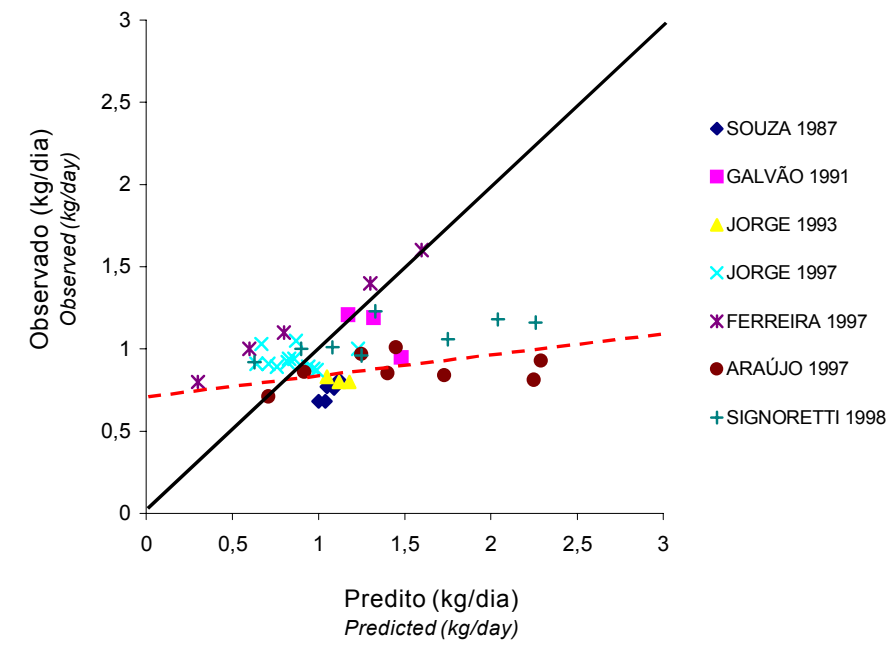

Figura 2 - Relação entre os ganhos observados e preditos pelo CNCPS para os trabalhos estudados. A linha contínua representa a relação ideal $(Y=X)$ e a linha pontilhada é a regressão linear $Y_{\text {OBS }}=0,820324$ $+0,118537 X_{\text {CNCPS }}$, em que Yéoganho observado e X, o ganho predito pelo CNCPS.

Figure 2 - Relation among observed and predicted intakes by CNCPS for all studied experiments. The continuous line represent the ideal relation $(Y=X)$ and the discontinuous line is the linear regression $Y_{O B S}=$ $0.820324+0.118537 X_{C N C P S}$, where $Y$ is the observed intake and $X$ is the predicted intake by CNCPS. 
(1994) e FERREIRA (1997), sendo que a amplitude dessas diferenças pode estar relacionada à alimentação, ao grau de sangue, à idade de abate, à condição sexual, entre outras características que devem ser consideradas, quando se pretende utilizar o CNCPS como predidor do ganho de peso.

\section{Conclusões}

Os consumos foram preditos adequadamente pelo CNCPS, enquanto os ganhos de peso preditos apresentaram resultados variáveis, de acordo com as características da alimentação e dos animais.

\section{Referências Bibliográficas}

ARAÚJO, G.G.L. Consumo, digestibilidade, desempenho, composição corporal e exigências nutricionais de bezerros alimentados com dietas contendo diferentes niveis de volumoso. Viçosa, MG, 1997. 104p. Dissertação (Doutorado em Zootecnia) - Universidade Federal de Viçosa, 1997.

FERREIRA, M.A. Desempenho, exigências nutricionais e eficiência de utilização da energia metabolizável para ganho de peso de bovinos F1 Simental x Nelore. Viçosa, MG. 97p. Dissertação (Doutorado em Zootecnia) - Universidade Federal de Viçosa, 1997.

FOX, D.G., SNIFFEN, C.J., O'CONNOR, J.D. et al. 1990. The Cornell Net Carbohydrate and Protein System for Evaluating Diets. Part I-A model for Predicting Cattle Requeriments and Feedstuff Utilization. Search: Agriculture. Ithaca: Cornell Univ. Agr. Exp. Sta. No. 34, 128p.

GALVÃO, J.G.C. Estudo da eficiência nutritiva, características e composição física da carcaça de bovinos de três grupos raciais, abatidos em três estágios de maturidade. Viçosa, MG: UFV, 82p. Dissertação (Mestrado em Zootecnia) Universidade Federal de Viçosa, 1991.
JORGE, A. M. Desempenho produtivo, características e composição corporal e da carcaça de zebuínos de quatro raças, abatidos em diferentes estágios de maturidade. Viçosa, MG: UFV, 1997. 99p. Dissertação (Doutorado em Zootecnia) Universidade Federal de Viçosa, 1997.

JORGE, A. M. Ganho de peso, conversão alimentar e características da carcaça de bovinos e bubalinos. Viçosa, MG: UFV, 1993. 97p. Dissertação (Mestrado em Zootecnia) Universidade Federal de Viçosa, 1993.

LANNA, D.P.D., BOIN, C., FOX, D.G. Utilização do CNCPS para estimativa do desempenho animal e do valor nutricional do bagaço de cana tratado a pressão de vapor. In: REUNIÃO ANUAL DA SOCIEDADE BRASILEIRA DE ZOOTECNIA, 31, 1994, Maringá, PR. Anais...Maringá: SBZ, 1994.

MALAFAIA, P.A.M. Taxas de digestão das frações protéicas e de carboidratos de alimentos por técnicas "in situ”, "in vitro" e de produção de gases. Viçosa, MG: UFV, 1997. 82p. Dissertação (Doutorado em Zootecnia) - Universidade Federal de Viçosa, 1997.

SIGNORETTI, R.D. Consumo, digestibilidade, composição corporal, exigências nutricionais e eficiências de utilização da energia metabolizável para ganho de peso de bezerros Holandeses. Viçosa, MG: UFV, 1998. 157p. Tese (Doutorado em Zootecnia). Universidade Federal de Viçosa, 1998.

SOUZA, J.B. Substituição parcial e total do farelo de algodão pela uréia, em rações de novilhas mestiças, em regime de confinamento e sua economicidade. Viçosa, MG. 42p. Dissertação (Mestrado em Zootecnia) - Universidade Federal de Viçosa, 1987.

Recebido em: 08/01/01

Aceito em: 26/07/01 